Rapid Reviews COVID-19

\title{
Reviews: "Factors Driving Extensive Spatial and Temporal Fluctuations in COVID-19 Fatality Rates in Brazilian Hospitals"
}

Francisco Benita ${ }^{1}$, Michel Boufadel ${ }^{2}$

${ }^{1}$ Singapore University of Technology and Design, ${ }^{2}$ New Jersey Institute of Technology

Published on: Jan 26, 2022

License: Creative Commons Attribution 4.0 International License (CC-BY 4.0). 
To read the original manuscript, click the link above.

Summary of Reviews: This study focuses on the rising fatality rate of COVID-19 Gamma variant in Brazilian hospitals. The data reveals that the increasing fatalities are explained by changes in healthcare pressures rather than the Gamma variant itself.

Reviewer 1 (Francisco B...) | प्म००

Reviewer 2 (Michel B...) | |

\section{RR:C19 Strength of Evidence Scale Key}

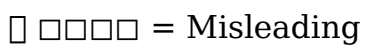

$$
\begin{aligned}
& \text { प्र } 40 \square=\text { Not Informative } \\
& \text { प्रा पि = Potentially Informative }
\end{aligned}
$$

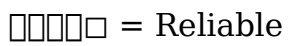

$$
\begin{aligned}
& \text { प्राप्र = Strong }
\end{aligned}
$$

To read the reviews, click the links below. 